\title{
DOMESTIC WORK OR WORKING AT INFORMAL SECTOR: A STUDY OF WOMEN IN SEMNAN \\ Soheila Alirezanejad
}

Associate Professor of Sociology, Islamic Azad University Garmsar Branch, Garmsar Iran.

Email: soal802001@gmail.com

Article History: Received on $20^{\text {th }}$ February 2021, Revised on $28^{\text {th }}$ April 2021, Published on $29^{\text {th }}$ April 2021

\section{Abstract}

Purpose: Present study aims to seek the reason why some women are working in the informal sector while the payment is meagre and there is neither insurance nor any bonus.

Methodology: Answering the above question, a mixed-method was designed (Grounded theory and survey). Data was gathered by using semi-structured interviews and questionnaires. Due to research limitations, quota sampling was used. During this research, 14 interviews were conducted with employed women in the informal sector. Discussions were open-ended. In addition, 180 questionnaires were filled out by participants.

Main findings: Findings indicated that these women have to choose between unpaid, endless domestic work and complex low-wage employment in the informal sector. They have to work because they want to have autonomy, and they feel a responsibility towards their family, especially their children. Despite the low payment, their job brought about a sort of empowerment for them. Working in the informal sector let them support their family and achieve emotional capital. If they do not work in the informal sector, they have to work at home as an unpaid worker of their family.

Application of the study: Women's employment in the informal sector has increased quickly during recent years, so examining their working conditions, especially from the point of view of salaries and benefits, can be effective in improving their living conditions

Novelty/Originality: The reason for the increase in demand for work in the informal sector, especially by women, is an issue that has never been explicitly addressed.

Keywords: Employment, Women, Informal Sector, Domestic Work, Semnan.

\section{INTRODUCTION}

The rate of unemployment is higher among women than men in Iran. Although some educated women can find a job, a more significant number are unemployed, and the labor market usually is gender-segregated. Women also have been experiencing social, cultural, or even legal restrictions for job opportunities. Shahla Haeri believes "The eight-year war with Iraq and its ... effects changed the dynamics of women's employment in Iran." She describes Women from poorer classes have usually worked as domestic laborers. Some women, mainly from the middle class, create their businesses and considerably revive the family income. She concludes women exhibited greater flexibility in the reversal of fortune in their families. Haeri correctly mentioned, "Formal economic sector was much slower in absorbing women into the labor force" (Haeri, 2013).

A few years after the war, in 1986, the rate of unemployment among men was $12.9 \%$, while in the same year, the ratio for women was $25.48 \%$. In the spring of 2010 , this rate reached $13.2 \%$ (for men) and $32 \%$ (for women). In 2011, this rate was $10.5 \%$ (for men) and $20.9 \%$ (for women). Such conditions will usually lead to the tendency for working in the informal sector for unemployed women. This means that many educated women are working temporary, unstable, parttime, or low wage (under minimum wage) jobs, with no insurance and bonus.

On the other hand, the Ministry of labor and social security has the least power of supervision in the informal sector. In $2007,25 \%$ of employed women received wages under the minimum legal wage. This rate reached $29.5 \%$ in 2008 . In 2016, more than $85 \%$ of employees informal sector were men, while less than $15 \%$ were women (Iranian Statistical Center, 2018). The data shows that most women had to work in the informal sector.

Women's employment in the informal sector has increased quickly during recent years. Because they do not get benefits from the government, union, or similar organizations, and their condition is getting even worse (Vijayasingham, 2020).. It seems that there is no chance for a decent job for those working in the informal sector.

These women are mostly well aware of their unequal and unjust payment despite their high capabilities and motivations. They are also mindful of the fact that their employment means fewer job opportunities for some men. So, why they continue their work under such conditions? What makes them continue working despite long working hours and unsuitable job conditions? Are they just needy, or are there other reasons?

\section{THEORETICAL REVIEW}

Castles believes the patriarchal family has been confronted with a severe challenge. This challenge relates to weakening continuous and persistent exercise of men's authority in the whole family. He points out women's employment as an influential factor. He also points out that women's communication skills cause more inclination for hiring them. He also 
mentions that women's flexibility is very effective in accepting part-time and temporary job opportunities (Castells, 1997). On the other hand, Allen Gilbert and Joseph Gagler conceive the informal sector as an antidote for the urban occupational problem. By investigating women workers' role in the informal sector, any job opportunity occupied by women rests on the lowest level of reward, wage, and social position.

Lilly Ladder has proceeded to investigate women's role in informal occupations in Malaysia. According to her study, from 1985 to 1992, on average, $27 \%$ of women who worked in the informal sector were married and had a child; they also had educated at the elementary level. Most of these women did not desire and decide to work in the informal sector, but they had to due to the lack of higher education or professional skills (Salarvandiyan, 2016). According to Labor World Organization's report, the number of employed women has been increasing compared with the past; however, they are still working at low-wage and vulnerable jobs without enjoying the direct social and legal support at their workplace (Kivimäki, 2020). Hematic investigations separated professional stability, compensation, working conditions, and business relationships as the primary contemplations for homegrown specialists. Bosses of homegrown specialists featured consistency with enactment, seeing the work as a component of the family, retirement arranging, and regarded as significant elements (De Villiers, 2019).

\section{Dominate a Field}

According to Bourdieu, field means production domain, allocation and rotation of goods, services, knowledge or competition situations and status. Actors are involved in collecting and restraining various kinds of capital. The most important field is the field of power. This is the space of relations based on force and compulsion among several types of money or among people who enjoy enough from one of the capitals to dominate an appropriate field (Swartz, 2019). As a result, those who have access to the highest capital will have power and higher social status. Agents and actors present in each field are unequal, based on their access to power and status. Therefore, these actors are usually competing based on quality and the form of capital they have access to. To show the social status of agents or social groups, Bourdieu refers to the relative value and importance of money authorized by persons and groups. He classified capital into four categories as follows:

A) Economic capital or production assets, which means having money and wealth.

B) The cultural capital is having and using cultural goods and services as well as knowledge.

C) Social capital is social and individual relations with other people.

D) Symbolic capital, which means having dignity, respect, and prestige (Swartz, 2019).

E) Bourdieu believed that capital itself allows a person to influence one's destiny and even others' (Swartz, 2019).

Some researchers believe that economic development progress may change the nature of jobs available for women. This point indicates that there may be a U-shaped relationship between women's labor force and economic development. A different idea suggests that social norms prevent women from accepting some jobs, which are considered masculine; also, there is a difference between married or unmarried women in such cases (Verick, 2018).

\section{Marginalization of women Work Force}

Neoliberalism has influenced structural features such as economic, social, cultural, and political aspects. According to neo-liberalism, a lack of efficiency in governmental organizations could cause poverty. It means governmental organizations' roles must be decreased in economic programs. One of the characteristics of neoliberalism is accessible business, bringing down money value, and removing supporting laws and employers' insurance. One of the most important effects of these policies in developing countries is the "marginalization of women in urban employment." In other words, women's roles in economic production will be decreased gradually, as follow:

1. Women have been forbidden from some specific jobs because of physical weakness and spiritual fragility, or lack of facilities;

2. Women often work in the informal sector along with low wage and unsafe occupations;

3. Some occupations are considered as feminine jobs where the number of women workers is very high, but they occupy meager positions;

4. Occupational differences such as low wage, lousy working condition and lack of distinction and occupational security in "feminine works"; is the fourth aspect of marginalization.

These policies have adverse effects on low-income classes, yet neo-liberalism has made more occupations for women. Throughout the world, women's income has increased for working outside the home (Dabrowski, 2021). "An idea implicit in the literature on female marginalization is that reductions in labor force participation and exclusion from formal sector jobs translate lower well-being for women (Mammen, 2000).

Suzan Goeke writes that women work very hard, but gender stereotypes conceive they are working to earn pocket money. Usually, men are considered as breadwinners of the family (Bahramitash, 2010). The neo-classic theory assumes 
that all wages are paid based on workers' efficiency in a competitive situation. Then gender wage differentiation may relate to the lower efficiency of women at work. This approach mentions that family resources are allocated for men's training and education, and women's duties such as housekeeping and baby-sitting do not need special training. Therefore, women have lower education and occupational experiments (Dabrowski, 2021). Accordingly, gender differences at work are related to different levels of human capital among men and women.

\section{Gender division of labor}

Radical feminists believe that all men take advantage of women's unpaid work at home. Also, they think men prefer to keep the traditional division of labor mostly. Despite working out of the house, employed women have to keep working at home (Giddens, 1993). Some researches in Iran and Saudi Arabia have shown that men tend to increase women's roles in daily family costs. These studies have also mentioned that almost all men benefit from women's income in daily expenses. Yet, they don't tend to promote or raise long-term investment, and they are unwilling to change the gender division of labor at home (Alirezanejad, 2016). Therefore, one expects that women's employment, even in the informal sector, might promote women's financial roles at home without significant changes in gender roles.

The gender relations approach shows that ethnic and gender discrimination usually creates new opportunities for employers to establish more profit. In addition, discharging men from feminine jobs stabilize low wage for women (Mammen, 2000). It can be said that decreased payment for masculine jobs can encourage women to do those jobs. Therefore, women's low wage in the informal sector is not the result of their insufficiency and incapability. In other words, by neglecting women, men will not take their positions (Litman, 2020).

It was uncovered that the force to be occupied with homegrown work is high among women who are less taught and have a place with the lower abundance quintile in the public arena (Singh, 2020). Concerning the approaches above and resort to reality, it is expected that by increasing women's tendency to make money, they will apply for jobs even in the informal sector, according to the present research. When women have more money, they provide more facilities for family members. In addition, they may give emotional capital for themselves (Adkins, 2004). Based on the vibrant capital employed, women expect more changes in the traditional division of labor. In addition, the persistent conventional division of labor may push women to work out of home, even in the informal sector.

\section{Conceptualization}

Economic capital is the variety of financial resources, including women's income, welfare facilities, ownerships, residence, cars, mobile, and bank deposits in general.

Max Weber describes power as a chance or opportunity, which helps a person succeed in achieving their desires and will happen despite the obstacles. Hence, power, in general, is a person's capability to dominate situations and control events. Power can be defined as controlling other people's behavior. This can be caused by fear, lack of capacity to act differently, loyalty, logic, indifference, or different motivations. According to the initial position, reputation and prestige are interpreted as one of the social power resources. However, it seems that distinction is not the same as power (Ritzer, 1992).

In the present study, the researchers inquire about indices such as independence, financial condition, assets, and satisfaction.

Employment is any physical and mental activity that conforms to the country's law or common law and is not prohibited. The move also is accomplished to earn income, and its consequence is commodity production or performing services (Piva, 2018). An employee is a person who receives wages in line with their activities. Overall, bits of knowledge into a portion of the critical battles of and possibilities for homegrown laborers in a specific setting - DWs who work in a uber city and various homes (as opposed to as live-ins)-were provided (Natarajan, 2018).

Money is an essential and fundamental meaning in modern society that facilitates the possibility of commodity exchange extensively. To understand the participants' control over money, we applied some questions, including how much money the employed women make? How do they spend their money?

Going out of home means attendance or presence in the outside community and performing a definite activity at a specific time. Facilities that all women offer to the family: all services that an employed woman provides to her family through her obtained income.

Antoney Giddens describes housework as "without wage work that is accomplished without direct payment and outside of a specific business domain. Oakley believes that domestic work is separating the house from the workplace. Generally, women undertake most housekeeping responsibilities, and men support the family financially (Giddens, 1993). It was proposed that across government assistance states, homegrown business strategies are still generally request-driven and support the conventional, uncommon nature of homegrown work - frequently at the specialists' cost (Jokela, 2017). 


\section{METHODOLOGY}

Conducting this research, a sequential inductive mixed method was designed. It has included qualitative (grounded theory) and quantitative stages (survey). Data gathering techniques in grounded theory are life history, semi-structured interviews to allow women to express their beliefs, behaviors, and memories, as well as their interpretations. A questionnaire implemented data gathering in the second phase (survey). It has been prepared based on the first stag's findings.

Unfortunately, there is no reliable data about Iranian women working in the informal sector, nor is there reliable data about these women in Semnan. About final inputs of the National Statistic Center of Iran, $61.49 \%$ of employed women in Semnan work in the formal sector (Iranian Statistical Center, 2018). Consequently, there was no chance to have an appropriate assessment of women who work in the informal sector. For this very reason, we have used quota sampling. During this research, 14 interviews were conducted with employed women in the informal sector. Discussions were open-ended. In addition, 180 questionnaires were filled out by participants.

\section{RESULTS AND DISCUSSION}

The obtained results showed certain concepts such as performing roles, sense of responsibility, independence, and empowerment.

These women mainly consider themselves as responsible for paying bills and expenditures of their family. This responsibility has led them to work in the informal sector. A 35 years old woman says: "my husband is unemployed, and I am in charge of the family; I have to pay bills." She complained about her husband's carelessness: "I undertake more responsibility than him, and I have nothing to do with him," A 39-year old separated educated woman said: "I have married two times, and I was unsuccessful in both ... I live with my son. Since his father doesn't take his custody, I look after him. Then I have to work even with low wage". A 28 -year old married woman said: "my husband doesn't have a permanent salary, so; I have to work to keep the family alive...."

Being responsible for securing their family makes some of these women give their little money to their husbands or fathers. A 24-year old single woman said: "I usually pay for what my family needs." She continued, "...I buy all stationery which my brothers and sisters need at Scholl." A 30-year old single woman said: "my parents have grown old... they can't prepare dowry for me, and I have to prepare it...." A 25-year old single woman said: "I paid for three semesters of my sister's tuition... I undertake many responsibilities as an older child...." These women usually allocate their income to ensure their family needs either directly or indirectly.

According to interviews, women have to work in the informal sector with low wages because men could not or did not want to pay the family cost.

Table 1: Participants' ideas about their responsibilities

\begin{tabular}{ll}
\hline $\begin{array}{l}\text { Lack of stable income for husband or father } \\
\text { Lack of men's profound motivations to ensure family cost }\end{array}$ & Needs of children or the other family members \\
\hline Tack care of children to grow up & To pay payments \\
\hline Prepare siblings' tuition & To buy dowry \\
\hline
\end{tabular}

In this survey, five items were measured by five things and categorized into three levels: a low range of responsibility, a middle range of responsibility, and a high degree of responsibility. The indicator ranges between 6 and 20. Table two states that only $7.2 \%$ of participants showed a low range of responsibility. About $93 \%$ of them showed middle and high degrees of responsibility.

Table 2: Range of responsibility

\begin{tabular}{llll}
\hline Level & Frequency & percentage & Cumulative frequency \\
\hline Low & 13 & 7.2 & 7.2 \\
\hline Middle & 123 & 68.3 & 75.6 \\
\hline High & 44 & 24.4 & 100 \\
\hline total & 180 & 100 & \\
\hline
\end{tabular}

The Chi-square test with a significance level of 0.03 shows a significant relationship between responsibility and marital status. Df equals six, and the value equals 3.970. This indicates substantial relation between these two concepts. It means that married women undertake more responsibilities than single ones.

These women own minimal assets and income, but this tiny little property obtained by hard indecent work gives them the power to influence their families' daily lives.

Table 3: Women's responsibility and marital status

\begin{tabular}{lllll}
\hline Level of responsibility & Low & Medium & High & total \\
\hline
\end{tabular}




\begin{tabular}{llllr}
\hline marital status & & & & \\
\hline Single & 1 & 51 & 24 & 76 \\
\hline Married & 9 & 62 & 18 & 89 \\
\hline Without spouse & 3 & 10 & 2 & 15 \\
\hline Total & 13 & 123 & 44 & 180 \\
\hline
\end{tabular}

Table 4: Level of women's assets and the facilities that a woman provides for her family

\begin{tabular}{llllllr}
\hline $\begin{array}{l}\text { level of facilities } \\
\text { which a woman } \\
\text { provide for her } \\
\text { family }\end{array}$ & Very low & low & average & High & $\begin{array}{l}\text { Very } \\
\text { high }\end{array}$ & total \\
\hline Low & 17 & 9 & 1 & 0 & 2 & 29 \\
\hline Medium & 69 & 27 & 16 & 7 & 3 & 122 \\
\hline High & 14 & 4 & 4 & 3 & 4 & 29 \\
\hline Total & 100 & 40 & 21 & 10 & 9 & 180 \\
\hline
\end{tabular}

According to data presented in table 4 (chi-square test shows a significant relationship between two concepts by sig equal to 0.04 , df equal to 1 , and value equal to 4.231 ), the higher the wealth, the more affordable, the more facilities are available to the family (especially children).

This behavior can be due to women's sense of responsibility towards the family. Thus, it can be stated that women tend to work in the informal sector due to the low income of fathers or spouses. Their income is mainly allocated to the necessities of family members.

One of the essential concepts, which we learned, was women's sense of independence. It seems to make money, and probably deciding on spending gives them a reason to find themselves independent. A 25 -year old single woman said: "I would like to wear various clothes ... When I have my own money, I feel independent. No one has the right to judge me. It is my own decision..." A 44-year old divorced woman said: "my profession (she was a cook) brings me economic independence and makes me decide independently...." She continued, “...When one is financially independent, she can spend money for her social improvement... if one is not financially dependent, she may not become socially independent." A 30-year old single woman who was a secretary said: "... employment increases my awareness. Even though my wage is meager but I am an independent woman now. This situation is much better than relying on others...."

About severe job opportunities' limitations, women with higher education have to accept low wages, unsuitable and uncertain jobs. A 39-year old educated woman said: "I grow up in a patriarchal family, and I had no power, and right to make my own choices... when I changed my life and got a job ... I felt independence." Another woman said: "financial independence could help me go for my desires such as having higher education...."

Employment, even with meager wages, may cause a kind of financial independence for women. On the other hand, it seems that the sense of independence has increased their tendency to go out of the home. Employment helps women to enjoy their education and specialty. The critical point is that the definition of independence has not kept them away from supporting their children or other family members. A 25 -year old single woman with elementary education said: "When I help my family, I feel independent because my family's honor is my honor..." A 32-year old married woman said: "... independence is a life improvement. I have freedom ... since I am working, I don't need any help from anyone. I like this situation". A 37-year old single woman who is a hairdresser said: "my brother and I are living together. Our family is living in a village. When my father is not here, I take care of my brother. I provide everything for him. I feel independent because my father trusts me...." A 28-year old single woman said: "I feel independent because I can help my family go on a journey and spend money for them." A 32-year old married, educated woman said: "nowadays ... I am afraid of my future social situation... fear from future makes me think that a woman should work and be financially independent."

It should be noted that when these women were using the concept of "financial independence," they might have considered different descriptions. Some of them felt confident and secure; for example, women who were working before marriage preferred to keep their financial privilege after marriage. Some were thinking about preparing their dowry. In addition, many were wondering what they should do if they are divorced. They need to be financially independent. "Fear from the future" was a painful social emotion among them. These women believed they must have been ready for being old and alone. Even married women thought of their situation after their husbands passed away or betrayed them. They think about the lack of any guardian, even their children. They believed that having their permanent income could be the safest situation. Financial independence allows them to make a decision and intervene against family and job difficulties. The participants mostly believed that employment made it possible to achieve economic independence and opportunities for social participation. It also has allowed them to step beyond their typical and traditional roles and gain a better and more valuable social situation. 
Table 5: Sense of independence

\begin{tabular}{llll}
\hline Level & Frequency & Percentage & Cumulative frequency \\
\hline low & 6 & 3.3 & 3.3 \\
\hline moderate & 110 & 61.1 & 64.4 \\
\hline High & 64 & 35.6 & 100 \\
\hline total & 180 & 100 & \\
\hline
\end{tabular}

During the survey, the sense of independence was constructed with twelve items divided into three categories: low, medium, and high; the range was between a minimum of 20 and a maximum of 57 . Based on these data, 3.3\% of respondents have a low sense of independence, $61.1 \%$ are moderate, and $35.6 \%$ are highly independent.

Table 6: Crosstab sense of independence and facilities, which a woman provides for her family

\begin{tabular}{llllr}
\hline Facilities for family & \multicolumn{3}{l}{ Sense of independence } & \multirow{2}{*}{ Total } \\
\cline { 2 - 5 } & Low & Medium & High & \\
\hline Low & 4 & 21 & 4 & 29 \\
\hline Medium & 2 & 81 & 39 & 122 \\
\hline High & 0 & 8 & 21 & 29 \\
\hline Total & 6 & 110 & 64 & 180 \\
\hline
\end{tabular}

The survey findings also indicate a positive and significant relationship between the women's sense of independence and the facilities that they provide to their families. Perhaps this relationship is reflected by more decision-making abilities or the importance of emotional capital in their daily life. The survey showed that women's small financial successes had affected their decision-making fields at home. The Chi-square test also shows the relation between women's independence and their small economic successes. Sig is 0.00 , the degree of freedom four and the value.

Table 7: Crosstab between the level of women's asset and their sense of independence

\begin{tabular}{|c|c|c|c|c|c|c|}
\hline \multirow[t]{2}{*}{ sense of independence } & \multicolumn{5}{|c|}{ The asset level } & \multirow{2}{*}{ Total } \\
\hline & Meager assets level & Low & Medium & High & Very high assets level & \\
\hline Low & 5 & 1 & 0 & 0 & 0 & 6 \\
\hline Medium & 65 & 27 & 12 & 3 & 3 & 110 \\
\hline High & 30 & 12 & 9 & 7 & 6 & 64 \\
\hline Total & 100 & 40 & 21 & 10 & 9 & 180 \\
\hline
\end{tabular}

417/33. According to the results presented in table 7, the chi-square test shows significant (sig) of 0.001 , degree of freedom of 1 , and the value of 10.22 ; there is a positive relationship between the two concepts. Their small asset gave them a sense of independence and some opportunity to support their children and their family.

In this research, it has been observed that all facilities that a woman provides to her family give her some power at home. A 35-year old woman said: "my husband was in prison for about a year, and my family was forcing me to file for divorce, but I did not... during that period, I could pay for me and my daughter's expenses... I was feeling to be a powerful person." A 28-year old woman said: "my husband and I are like friends ... he asks my opinion and accept my word ... I feel powerful because he respects my word and I make the final decisions." Most women believed that regardless of the low salary they received, they were happy for having a sense of being powerful." A 38-year old woman said: "... lonely women can continue their lives ... although my wage is meager, my money gives me power." A 44-year old woman said, "I feel powerful because I could continue my life with my job...." A 30-year old woman said, “... at work; I do not let anybody violate against my rights... I am powerful..." A 35-year old woman said: "everyone should work to live."

According to interviews, even low wages gave women a sense of power. Higher education also made them feel powerful. One of the participants said: "my education promotes my social position." Being seen is an essential element in the process of empowerment. The facilities that they can provide to their family were points that all women in the study mentioned. This matter has increased their influence at home. Anyone who can afford more services and facilities for the family enjoys more sense of power. For example, a 44-year woman who was a servant said, "My husband doesn't work. He is always at home... when I go home, and I have bought something, he is very kind to me" this woman conceives that when she earns money, her husband behaves better. It seems that providing facilities has brought her respect.

Table 8: Distribution of sense of powerfulness

\begin{tabular}{lllll}
\hline Variable & Frequency & Percentage & Valid percent & Cumulative frequency \\
\hline Low & 23 & 12.8 & 12.8 & 12.8 \\
\hline Medium & 113 & 62.8 & 63.8 & 76 \\
\hline
\end{tabular}




\begin{tabular}{lllll}
\hline High & 43 & 23.9 & 24 & 100 \\
\hline Total & 180 & 100 & 100 & \\
\hline
\end{tabular}

In the survey, power has been measured by a sample of twenty-three items. The scores were divided into three categories: low, moderate, and high; the range was ranged between a minimum of 25 and a maximum of 55. Table 9 shows that $12.8 \%$ of the participants felt low power, and $85.7 \%$ felt moderate or high. Women with more economic capital will have higher power over their husbands, and relationships in such families might be fair.

Table 9: Frequency distribution of women by the level of income

\begin{tabular}{lllll}
\hline Level & Frequency & Percentage & Valid percent & Cumulative frequency \\
\hline Meager income & 100 & 55.6 & 55.6 & 55.6 \\
\hline Low & 40 & 2.22 & 2.22 & 77.8 \\
\hline Medium & 21 & 11.7 & 11.7 & 89.4 \\
\hline High & 10 & 5.6 & 5.6 & 95 \\
\hline Very High income & 9 & 5 & 5 & 100 \\
\hline Total & 180 & 100 & 100 & \\
\hline
\end{tabular}

The women's income and asset index were classified into five categories: the first group lacked assets or a shallow range of assets; the second category was low; the third group was moderate; the fourth group was high, and the fifth group had very high support. Their income has been their most important asset.

Table 10: Crosstab the woman's sense of power and level of assets

\begin{tabular}{lllllllr}
\hline \multirow{2}{*}{ Sense of Power } & \multicolumn{6}{c}{ Level of Assets } & \multirow{2}{*}{ Total } \\
\cline { 2 - 6 } & \multirow{2}{*}{ Meager income } & low & Medium & \multirow{2}{*}{ High } & Very high assets level & \\
\hline Low & 17 & 5 & 1 & 5 & 17 & 113 \\
\hline Medium & 59 & 28 & 15 & 28 & 59 & 43 \\
\hline High & 23 & 7 & 5 & 7 & 23 & 180 \\
\hline Total & 99 & 40 & 21 & 40 & 99 & \\
\hline
\end{tabular}

According to the results of table 10 (the Chi-square test shows a value of 5/458 with a significant level (sig) of 0.019 and a degree of freedom of 1). One can say that there is a positive relationship between the status of women's asset and their sense of power.

Table 11: Frequency distribution of women according to the facilities that a woman gives to her family.

\begin{tabular}{lllll}
\hline Variable & Frequency & Percentage & Valid percent & Cumulative frequency \\
\hline Low & 29 & 16.1 & 16.1 & 161 \\
\hline Medium & 122 & 67.8 & 67.8 & 83.9 \\
\hline High & 29 & 16.1 & 16.1 & 100 \\
\hline Total & 180 & 100 & 100 & \\
\hline
\end{tabular}

This index is made up of three items, and it is divided into three categories: low, moderate, high, with a minimum of four and a maximum of 14. The findings of the survey show that if the facilities provided by the woman to the family increase, their power at home will also increase - also the higher the level of women's asset, the more the facilities provided to the family.

Domestic work is usually unpaid. Generally, all women, including homemakers and employed women, are doing domestic jobs. Domestic work is endless and usually is not evaluated as employment. All interviewees believed that there had been much more pleasure in working out of the home than housekeeping. A 32-year old woman said: "When I stay at home, I feel depressed, but when I am outside, I don't think about any of my problems." A 30-year old woman said: "home is an environment which bores me, but when I am working out, there is no such feeling." A 33-year old woman said: "working out of home gives me the chance to be far from my husband and then have fewer struggles with him...." A 35-year old woman said: "house chores never finish, and that is depressing. When I was young, I wished I had been a man because I hadn't known that women could work outside the home." A 28 -year old woman said: "I can't stay at home... I know that when I am at work, I receive a monthly salary. Having a job gives me this chance to be out of the home." A 30-year old woman said: "When I am at home, I can't tolerate the atmosphere." A 44-year old woman said: "housekeeping has no wage, but when I am working, I receive my salary." It seems that despite low wages, working in the informal sector provides new opportunities for these women, and they prefer to be out of home and make little money. Apparently, domestic routine is tedious work without any income and appreciation. This bores the women while the hard work with low wages in the informal sector gives them some hope and opportunity for the future. 
Table 12: Reasons for leaving home

\begin{tabular}{ll}
\hline Feel bored and stagnation at home & do not think about problems \\
\hline household chores don't finish at any time & Have distance with husband \\
\hline The tedium of domestic work at home & Having salary \\
\hline Anxiety at home & New expectations and needs \\
\hline & Unpaid domestic work \\
\hline
\end{tabular}

In the conducted interviews, most of the educated women considered employment as an essential factor using their expertise and education. They also believe employment, even in the informal sector, make them feel more secure and efficient.

We also noticed that the woman's willingness to be out of a home could be computed with six items which were divided into four categories: low, medium, high, and very high. There was no relationship between the level of education and women's inclination to work in the informal sector. In other words, women, regardless of having a university education, preferred to work in the informal sector in comparison with staying at home. It should be noted that higher education for women in the informal sector does not bring more money. In other words, education, as previously mentioned, increases their willingness to be an employee, but they do not earn more money.

Table 13: Frequency of women's reports about domestic work pressure

\begin{tabular}{lllll}
\hline Variable & Frequency & Percentage & Valid percent & Cumulative frequency \\
\hline Low & 30 & 16.7 & 16.7 & 16.7 \\
\hline Medium & 90 & 50 & 50 & 66.7 \\
\hline High & 60 & 33.3 & 33.3 & 100 \\
\hline Total & 180 & 100 & 100 & \\
\hline
\end{tabular}

It was previously reported by participants that domestic work is erosive and tedious. They wanted to get out of home, but we needed to know if it would have changed their roles at home. Most of the interviewees talked about the pressure of domestic parts and duties. This feature can be measured by four sets of items, which were divided into three categories: low, moderate, high; the ratio was ranged between a minimum of 10 and a maximum of 24 . Overall, $16.7 \%$ of the respondents evaluated the pressure of domestic work as low. However, about $80 \%$ of the participants considered domestic labor pressure to be moderate or high.

Employed women in the informal sector experience low wages from the beginning. Meanwhile, a significant part of urban employed women in developing countries is actually working in the informal sector. Most of these women encounter serious problems. A 30-year old single woman said: "I experience many indecencies in my job...." A 35-year old single woman has complained about long working hours. A 31-year old married woman said: "My supervisor does not work properly and honestly. Then I have to accomplish his duties as well as mine. My duties are doubled. I am exploited unfairly." Another 31-year old woman said: "I had been on maternity leave for only one month. Since then, I have to take care of my newborn baby at the workplace..." She was a secretary. She also complained about low salary and some daily difficulties for commuting between home and work. A 26-year old woman said: "I cannot stop working even for a moment ... because the machine is always running ... printing and cutting... I am obliged to work while standing from 7:00 AM till 6:00 PM." A 38-year old woman said: "I have to spend a lot of money on my health issues in the near future, namely for backache, sore feet, and eye diseases." A 33-year old woman said: “... I have to work double shifts...." A 35 woman said, "I am unfortunate because I haven't any insurance ... I have no proper work prospects."

These women preferred to work in the informal sector despite all problems in comparison with staying at home. They save part of their low income since they have learned it since they have been little girls (Alirezanejad, 2016).

\section{CONCLUSION}

Nowadays, the informal sector is an important sector of the economy and workforce market in developing countries. Since women's participation in the workforce market is increasing, especially in the informal sector, it cannot be neglected. Employed women in the informal sector receive low salaries, and they do not benefit from insurance. They also are unfairly exploited. Yet, they prefer to work rather than staying at home. Homemade products are not sold in the bazaar. It is consumed very fast, and it does not bring any money for the woman. Domestic work is considered as lowvalue work and does not bring promotion at home and in the community. These women's husbands or fathers are primarily unemployed, or they are seasonal workers, then the women have to earn money.

Being employed in the informal sector, they are able to support their family. They feel more powerful while performing new responsibilities in the family. Despite low incomes, these women achieve a sense of independence. Their money also let them be part of the decision-making process for the families' daily life. So, they tend to continue their economic activities with low payment and other problems. Women's employment in the informal sector and having an income are essential to ensure family needs. These women also experience independence, freedom, ownership, and responsibility. 
They usually have few opportunities to work in the formal sector. In fact, they have to choose between unpaid domestic work at home and low-wage hard work in the informal sector.

\section{REFERENCES}

1. Adkins, L. S., B. (2004). Feminism after Bourdieu. Blackwell Publishing.

2. Alirezanejad, S., Khakpoor, S. (2016). A gender analysis on spending and saving money among families in Tehran. Women in politics and development, 13(2), 151-170.

3. Bahramitash, R. (2010). Challenges with the Neoliberal Economy: (gender and Globalization in Southeast Asia). SAMT Publishing House.

4. Castells, M. (1997). The Power of Identity (The Information Age: Economy, Society and Culture, Volume II).

5. Dabrowski, V. (2021). Neoliberal feminism': Legitimising the gendered moral project of austerity. The Sociological Review, 69(1), 90-106. https://doi.org/10.1177/0038026120938289

6. De Villiers, B., Taylor, M. (2019). . S, 17, 13. (2019). Promoting a positive work experience for South African domestic workers. SA Journal of Human Resource Management, 17(13), 4102. https://doi.org/10.4102 /sajhrm.v17i0.1206

7. Giddens, A. (1993). Sociology, Anthony Giddens (Second Edition). Polity Press in association with Blackwell Publishers.

8. Haeri, S. (2013). No End in Sight: Politics, Paradox, and Gender Politics in Iran. Boston University Law Review. Panel V: International Perspectives, 93, 1047.

9. Iranian Statistical Center (2018). Employed women statistics in Iran.

10. Jokela, M. (2017). The role of domestic employment policies in shaping precarious work. Social Policy \& Administration, 51(2), 286-307.

11. Kivimäki, M., Virtanen, M., Nyberg, S. T., Batty, G. D. (2020). The WHO/ILO report on long working hours and ischaemic heart disease - Conclusions are not supported by the evidence. Environment international, 144, 106048. https://doi.org/10.1016/i.envint.2020.106048

12. Litman, L., Robinson, J., Rosen, Z., Rosenzweig, C., Waxman, J., Bates, L. M. (2020). The persistence of pay inequality: The gender pay gap in an anonymous online labor market. PloS one, 15(2), e0229383. https://doi.org/10.1371/journal.pone.0229383

13. Mammen, K., Paxson, C. (2000). Women's Work and Economic Development. Journal of Economic Perspectives, 14(4), 141-164.

14. Natarajan, B., Rajesh, J. (2018). Domestic Workers and the Challenges of Collective Action in Informal Work. Centre for Sustainable Employment Working Paper.

15. Piva, M., Vivarelli, M. (2018). Technological change and employment: is Europe ready for the challenge? Eurasian Bus Rev, 8, 13-32. https://doi.org/10.1007/s40821-017-0100-x

16. Ritzer, G. (1992). Sociological Theory (Third Edition). McGraw-Hill.

17. Salarvandiyan, F., Hosseini, S.A. Habibi, L., Jafari Mehrabadi, M. (2016). The role of informal jobs in relieving informal settlement (case study: hesaramir of pakdasht). Journal of Urban Economics and Management, 4(14), 137-157.

18. Singh, P., Pattanaik, F. (2020). Unfolding unpaid domestic work in India: Women's constraints, choices, and career. Palgrave Communications, 6(1), 1-13.

19. Swartz, D. L. (2019). Bourdieu's Concept of Field in the Anglo-Saxon Literature. In J. Blasius, Lebaron, F., Le Roux, B., Schmitz, A. (Ed.), mpirical Investigations of Social Space. Methodos Series (Methodological Prospects in the Social Sciences) (Vol. 15). Springer, Cham. https://doi.org/10.1007/978-3-030-15387-8 11

20. Verick, S. (2018). Female labor force participation and development IZA World of Labor(87v2), 1-11. https://doi.org/10.15185/izawol.87.v2

21. Vijayasingham, L., Govender, V., Witter, S., Remme, M. (2020). Employment based health financing does not support gender equity in universal health coverage. BMJ (Clinical research ed.), 371, m3384. https://doi.org/10.1136/bmj.m3384 